OPEN ACCESS

Edited by:

S. M. Mansour Haeryfar,

Western University, Canada

Reviewed by:

Masaki Terabe,

National Institutes of Health, USA

Susanna Cardell,

University of Gothenburg, Sweden

Jay A. Berzofsky,

National Institutes of Health, USA

*Correspondence: Vipin Kumar

Laboratory of Immune Regulation, Department of Medicine, University of California San Diego, 9500 Gilman Drive, La Jolla, CA 92037, USA vckumar@ucsd.edu

Specialty section:

This article was submitted to T Cell Biology, a section of the journal

Frontiers in Immunology

Received: 01 April 2015 Accepted: 02 June 2015

Published: 17 June 2015

Citation:

Marrero I, Ware R and Kumar V (2015) Type II NKT cells in

inflammation, autoimmunity, microbial immunity, and cancer.

Front. Immunol. 6:316.

doi: 10.3389/fimmu.2015.00316

\section{Type II NKT cells in inflammation, autoimmunity, microbial immunity, and cancer}

\author{
Idania Marrero, Randle Ware and Vipin Kumar* \\ Laboratory of Immune Regulation, Department of Medicine, University of California San Diego, La Jolla, CA, USA
}

Natural killer T cells (NKT) recognize self and microbial lipid antigens presented by non-polymorphic CD1d molecules. Two major NKT cell subsets, type I and II, express different types of antigen receptors (TCR) with distinct mode of CD1d/lipid recognition. Though type II NKT cells are less frequent in mice and difficult to study, they are predominant in human. One of the major subsets of type II NKT cells reactive to the self-glycolipid sulfatide is the best characterized and has been shown to induce a dominant immune regulatory mechanism that controls inflammation in autoimmunity and in anti-cancer immunity. Recently, type II NKT cells reactive to other self-glycolipids and phospholipids have been identified suggesting both promiscuous and specific TCR recognition in microbial immunity as well. Since the CD1d pathway is highly conserved, a detailed understanding of the biology and function of type II NKT cells as well as their interplay with type I NKT cells or other innate and adaptive T cells will have major implications for potential novel interventions in inflammatory and autoimmune diseases, microbial immunity, and cancer.

Keywords: CD1d, innate immunity, inflammation, autoimmunity, cancer, sulfatide, lipids, neutrophils

\section{Introduction}

Natural killer T (NKT) cells are innate-like T cells that recognize both exogenous and endogenous lipid antigens presented by $\mathrm{CD} 1 \mathrm{~d}$, a major histocompatibility (MHC) class I-like antigen-presenting molecule. They comprise two main subsets, type I and type II, based upon differences in the nature of their T cell receptors (TCRs) (1-3). The well-studied type I NKT cell subset that uses a semi-invariant TCR $\alpha$ chain is more prevalent than the type II subset in the mouse, while the less explored type II NKT cell subset that utilizes a more diverse TCR repertoire is predominant in humans (4-6). Both subsets require signaling lymphocytic activation molecule-associated protein (SAP) and promyelocytic leukemia zinc finger (PLZF) for their development and effector program $(3,7,8)$. After antigenic activation, NKT cells secrete large amounts of cytokines, such as interferon- $\gamma$ (IFN $\gamma$ ), interleukins IL-4, IL-10, IL-13, IL-17, and IL-22, tumor necrosis factor- $\alpha$ (TNF $\alpha$ ), and granulocyte-macrophage colony-stimulating factor (GM-CSF), which modulate immune responses triggered by other innate NK cells and adaptive T and B cells (3-6). Both subsets appear to modulate immune responses involved in autoimmunity, inflammation, infections, and cancer $(4-7,9,10)$. This review primarily focuses on lipid-reactive CD1d-restricted TCR $\alpha / \beta+$ type II NKT cells and their potential role in immunity. 


\section{Antigen Recognition, TCR Repertoire, and Activation of Type II NKT Cells}

Type I NKT cells respond to a strong agonist $\alpha$-galactosylceramide $(\alpha \mathrm{GalCer})$ as well as microbial and self-lipids. By contrast, type II NKT cells are not reactive to $\alpha \mathrm{GalCer}$ and recognize selfglycolipids and self-phospholipids $(5,6,11)$. A major subset of type II NKT cells recognize a naturally occurring self-glycolipid, sulfatide, which is enriched in several membranes, including myelin in the central nervous system (CNS), $\beta$-cells in the pancreas, kidney, and liver $(12,13)$. Recently, other self-lipids, including $\beta$-D-glucopyranosylceramide ( $\beta$-GlcCer), $\beta \mathrm{GalCer}$, lysophosphatidylethanolamine (lyso-PE), lysophosphatidylglycerol (lyso-PG), or cardiolipin and lysophosphatidylcholine (lyso-PC) have been shown to be involved in the activation of liver type II NKT cells $(5,6,8,12-17)$. Lyso-PC and $\beta$-glucosylceramide and glucosylsphingosine lipids were reported to activate human type II NKT cells as well $(18,19)$.

The mechanism of binding of type II NKT TCRs to antigens uses features of TCR binding shared by both type I NKT cells and conventional $\mathrm{T}$ cells, but also is distinct from both $(12,20,21)$. Thus, type II NKT TCRs contact their ligands primarily via their $\beta$ chain rather than $\alpha$ chain, suggesting that the TCR V $\beta$ chain contributes significantly to antigen fine specificity (20). Sulfatidereactive type II NKT cells express oligoclonal TCRs with a limited number of $V \alpha$ - and $V \beta$-chains $(V \alpha 3 / V \alpha 1$ and $V \beta 8.1 / V \beta 3.1)$. In contrast to the germline-encoded TCR $\alpha$ chain in type I NKT cells, only about $14 \%$ of TCR V $\alpha$ and $13-27 \%$ of TCR V $\beta$ chains in type II NKT cells are encoded by germline gene segments (12). A prevalent type II NKT cell subset expressing V $\alpha 3.2-\mathrm{V} \beta 8$ TCR has also been described (22). It remains to be seen whether other type II NKT cells will also use a similar mechanism of lipid recognition to sulfatide-reactive T cells. It appears that type II NKT cells are mostly reactive to self-lipid ligands, but they can also recognize structurally similar microbial-derived lipids because of their TCR degeneracy or promiscuity.

Type I NKT cells can be activated either directly through TCR stimulation by exogenous microbial lipid antigens or indirectly by stimulatory self-lipids presented by CD1d and/or cytokines (IL-12, IL-18, or type I IFN) produced through Toll-like receptor (TLR)-mediated signaling $(23,24)$. Thus, different self-lipids as well as cytokines present at elevated levels during inflammation can potentially stimulate type I NKT cells. Recent studies suggest that type I NKT cells can be activated in response to bacteria, as well as viruses, without antigen receptor stimulation (25). By contrast, type II NKT cells are mainly stimulated by direct recognition of lipid/CD1d complexes by their TCR. It has been consistently found that stimulation of type II NKT hybridomas with phospholipids and glycolipids requires lipid uptake, intracellular processing, and presentation to TCR but not TLR signaling $(15,26)$. In many experimental conditions wherein type I NKT cells are activated, type II NKT cells remain inactivated suggesting that type II NKT cells may not be easily activated by cytokine/TLR signaling but require self-lipid recognition.

It is becoming clear that the TCR recognition by type II NKT cells can be highly specific or promiscuous. For example, sulfatide-reactive type II NKT cell hybridomas XV19 or 19.3 can recognize sulfatide or lyso-PC effectively but not so efficiently all other phospholipids or glycolipids $(12-15,17,26)$. Consistent with this, at the polyclonal level, some lyso-PC-reactive NKT cells are distinct from sulfatide-reactive NKT cells (17) and in 4get mice, type II NKT cells are reactive to several self-lipids but not sulfatide $(8,16)$. Similarly, some lyso-PG-reactive type II NKT hybridomas can recognize both self and microbial lipids derived from Mycobacterium tuberculosis or Corynebacterium glutamicum and others are non-responsive to these lipids (15). These findings identify some redundancy as well as overlapping TCR repertoires among type II NKT cells that recognize self-lipids.

Immune regulatory activity of NKT cells can be mediated by cytokines secreted by NKT cells themselves or following their interaction with other immune cells, including DCs, NK cells, Tregs, monocytes, and B cells. Activation of NKT cell subsets can result in the deviation of a cytokine secretion profile in MHCrestricted $\mathrm{CD}^{+} / \mathrm{CD}^{+} \mathrm{T}$ cells toward either a pronounced $\mathrm{Th} 1-$, Th2-, or Th17-like response.

It is noteworthy that in inflamed target tissues, such as in pancreas in non-obese diabetic (NOD) mice that spontaneously develop type 1 diabetes (T1D) and in the CNS during experimental autoimmune encephalomyelitis (EAE), both type I and type II NKT cells accumulate $(13,27)$. However, activation of type II NKT cells following sulfatide or lyso-PC administration leads to a rapid accumulation of type I NKT cells into liver in an IL-12 and macrophage inflammatory protein 2 (MIP2)-dependent fashion. But these recruited type I NKT cells are neither activated nor do they secrete cytokines, and consequently they are anergic, leading to decreased levels of IFN $\gamma$ followed by reduced recruitment of myeloid cells, NK cells, and protection from liver damage $(28,29)$. In contrast to the activation of lyso-PE-reactive type II NKT cells in an infectious model of HBV, hepatic type I NKT cells are not anergized but stimulated to secrete cytokines (16). This difference in type I NKT stimulation may relate to the differential milieu in liver during sterile versus infectious immunity.

\section{A Novel Type II NKT Cell-Mediated Immune Regulatory Pathway}

Sulfatide-mediated type II NKT cell stimulation in vivo results in the activation of predominantly hepatic plasmacytoid DCs (pDC) but not conventional DC ( $\mathrm{cDC}$ ) and ultimately induction of anergy in hepatic type I NKT cells. This unique immune regulatory pathway not only involves cross-regulation of type I NKT cells but also inhibition of pathogenic Th1/Th17 cells through tolerization of hepatic CDC and tissue-resident antigen-presenting cells (APCs), such as microglia in the CNS $(28,30)$. By contrast, activation of type I NKT cells following $\alpha$ GalCer administration predominantly activates hepatic $\operatorname{cDC}(28,29)$. We are currently investigating the molecular mechanism of these NKT-DCs interactions.

It has been shown that this immune regulatory pathway effectively controls EAE, T1D, inflammatory liver diseases, and systemic lupus erythematosus (SLE) $(17,27,28,30-32)$ (Halder, unpublished). A recent study has suggested that the ICOS and PD-1 ligand pathways are required for the regulation of T1D in NOD mice by $\mathrm{CD}^{+}$type II NKT cells (33). Sulfatide-mediated type II NKT cell activation can also result in IL-10 secretion and, 
consequently, inhibition of type I NKT cells and diabetogenic or encephalitogenic $\mathrm{CD}^{+}$and $\mathrm{CD} 8^{+} \mathrm{T}$ cells $(13,27)$. Furthermore, activation of type II NKT cells also induces alterations in other innate cells, including myeloid-derived suppressor cells (MDSCs), $\mathrm{CD} 11 \mathrm{~b}^{+} \mathrm{Gr}-1^{+}$cells, and neutrophils $(17,28,30-32)$. Accordingly, MDSCs have been shown to protect mice from EAE (34). $\mathrm{CD} 11 \mathrm{~b}^{+} \mathrm{Gr}-1^{+}$cells and neutrophil alterations can also protect from inflammatory liver diseases $(31,32,35)$. Additionally, activation of type II NKT cells by PD-L1-deficient DCs increases the IL-4 and IL-13 levels and, consequently, decreases the numbers of IFN $\gamma$ and IL-17-secreting pathogenic T cells (36). Thus, targeting type II NKT-mediated inhibition of the effector functions of Th1/Th17 cells and APCs in peripheral organs as well as in affected target tissues offers a potent strategy for intervention in autoimmune and inflammatory diseases (30).

\section{Type II NKT Cells in Autoimmune and Inflammatory Diseases}

The activation of type II NKT cells with sulfatide controls both antigen-induced and spontaneously arising autoimmune diseases. Additionally, sulfatide-mediated immune regulation inhibits inflammatory liver diseases elicited by type I NKT cells $(13,17$, 27, 28, 30-32, 35). Sulfatide-reactive type II NKT cells also have been shown to abrogate ischemic-reperfusion injury in mice and in patients with acute tubular necrosis (37). Interestingly, during EAE and T1D progression, sulfatide-reactive type II NKT cells accumulate in the target tissue and in the draining of lymph nodes, respectively. This greater abundance of type II NKT cells in the CNS inverts the usual ratio of type II/type I NKT cells (type II NKT cells, 3-4\%, and type I NKT cells, 0.6-0.9\%) (13, 27). Thus, administration of brain-derived sulfatides or synthetic cic-tetracosenoyl or tetracosenoyl sulfatide affords protection from EAE and diabetes $(13,27,30)$. In both cases, it is the sulfatide with the longer fatty acid chain that is able to efficiently activate type II NKT cells and prevent autoimmunity. These data suggest that sulfatide analogs should be examined in clinical studies in multiple sclerosis (MS) and T1D. Our preliminary studies also suggest that activation of type II NKT cells following administration of sulfatide significantly inhibits development of lupus nephritis in (NZB X NZW) F1 mice, further indicating a regulatory role of type II NKT cells (5) (Halder, unpublished).

Recent studies have indicated key mutual interactions among NKT cells, CD1 d ${ }^{+}$cells, and commensal microbiota in the intestine (38). Evidence from several animal models of inflammatory bowel disease (IBD) demonstrates that type I NKT cells can be either protective or pathogenic (39). Interestingly, type II NKT cells seem to promote intestinal inflammation and mediate a pathogenic response when both CD1d expression and the frequency of IL-13 producing type II NKT cells are increased in mice as well as patients with ulcerative colitis (40-42). It is noteworthy that type II NKT cells involved in ulcerative colitis in humans are also reactive to lysosulfatide, but in contrast to the liver type II NKT cells, they secrete IL-13 and not IFN $\gamma$ (41). This suggest that there are subsets of type II NKT cells that may have different TCR repertoires as well as different cytokine secretion patterns in different tissues, just as there are different subsets of type I NKT cells.

\section{Type II NKT Cells in Metabolic and Liver Disorders}

Both NKT cell subsets have been shown to be involved in adipose-tissue inflammation, diet-induced obesity, and glucose metabolism (43). Roles for eosinophils, macrophages, and innate lymphoid type 2 cells (ILC2) have also been suggested in metabolic disorders $(44,45)$. More recently, type II NKT cells induced by both IL-25 and sulfatide treatments have been shown to be involved in the regulation of inflammation in adipose tissue and prevention of high fat diet-induced obesity in mice. Transfer of type II NKT cells into obese mice induced a greater and prolonged weight loss and improved glucose tolerance (44).

In inflammatory liver diseases, type I and type II NKT cells have been shown to play opposing roles (35). Earlier, it was shown that following liver injury after ischemic-reperfusion or ConA administration, a rapid activation of IFN $\gamma$-secreting type I but not type II NKT cells takes place $(28,31)$. Activation of type I NKT cells generates a cascade of events that contributes to liver inflammation and damage. The secretion of pro-inflammatory cytokines, such as IFN $\alpha$, and chemokines leads to accumulation of CD11b+ Gr-1+ cells as well as other myeloid cells resulting in the destruction of hepatocytes. By contrast, sulfatide-activated type II NKT cells inhibit the cascade of pro-inflammatory events through a mechanism that includes activation of $\mathrm{pDC}$ resulting in tolerization of cDC, anergy in type I NKT cells and consequently protection from liver injury $(28,31,35)$. In a mouse model of chronic alcohol liver disease (ALD), we have found that type I, but not type II, NKT cells are activated, leading to recruitment of inflammatory neutrophils and liver damage $(46,47)$. Inhibition of type I NKT cells following a novel direct mechanism involving all-trans retinoic acid (48) and its receptor (RAR- $\gamma$ ) signaling, or an indirect mechanism mediated by sulfatide-activated type II NKT cells significantly blunts ALD (46). Consistent with this, accumulation of activated type I NKT cells in patients with NAFLD has recently been shown (49-51). Currently, clinical studies are being carried out to examine the potential use of a RAR- $\gamma$ analog for the treatment of alcohol- and non-alcoholic liver disease. We are presently investigating in humans the role of both type I and type II NKT cells in the promotion as well as regulation of inflammatory immune responses in liver and gut. The identification of the role of these cell subsets in liver disorders could potentially lead to the development of novel therapeutics.

\section{Type II NKT Cells in Infectious Diseases}

Natural killer $\mathrm{T}$ cells contribute to the early immune response against a broad range of microbial pathogens, playing either a beneficial role in some infections or a negative role in others (52). Frequently, type I and type II NKT cells can have opposing roles in microbial immunity. For example, in the case of Trypanosoma cruzi infections, type II NKT cells were shown to promote inflammation and mortality and reduced titers of pathogen-specific antibodies, whereas type I NKT cells led to reduced inflammation and improved mortality and antibody titers (53). By contrast, during murine Schistosoma mansoni infection, type II NKT cells led to 
increased Th 2 cytokine secretion and decreased IFN $\gamma$ production, while type I NKT cells reinstated IFN $\gamma$ levels (54).

Sulfatide-activated type II NKT cells have also been shown to affect the course of infectious diseases. Previously, we showed that sulfatide-activated type II NKT cells inhibit HIV-1 replication and enhance multi-lineage hematopoiesis in a SCID-Hu (Thy/Liv) HIV model (55). We hypothesized that sulfatide-mediated activation of type II NKT cells and pDC results in the induction of anergy in type I NKT cells. It was shown that peripheral CD4 ${ }^{+}$type I NKT cells are depleted in early HIV infection and that the remaining cells in the circulation during HIV infection are functionally impaired in IFN $\gamma$ expression (56). Sulfatide-mediated activation of type II NKT cells also has a protective effect in a Staphylococcus aureus murine model of sepsis and is associated with a decrease in pro-inflammatory cytokines, such as TNF $\alpha$ and IL-6 (57). This beneficial outcome was found to depend on CD1d but not on type I NKT cells.

Recent studies in HBV infection in animal models and humans have shown that NKT cells contribute to the initiation of antiviral immune responses against $\mathrm{HBV}$. An early activation of type I and type II NKT cells was found following infection, mainly in the liver, which correlated with IFN $\gamma$-dependent suppression of viral replication; but also NKT cells contribute to HBV-induced hepatitis $(16,58)$. Using a mouse model of infection with HBV-expressing adenoviral particles (Ad-HBV), it was demonstrated that J $\alpha 18$-deficient (lacking type I NKT cells) and CD1d-deficient (lacking all NKT cells) mice exhibited a significant decrease in $\mathrm{NK}, \mathrm{B}, \mathrm{CD} 4^{+}$, and $\mathrm{CD}^{+} \mathrm{T}$ cell activation and hepatic immune infiltration, supporting the idea that NKT cells play a role in the immune response to HBV (16). More importantly, it was shown that HBV infection induces production of modified ER self-lipids, including phosphatidylethanolamine (PE) and lysophosphatidylethanolamine (lyso-PE), direct activation of liver type II NKT cells, and downstream cytokine-dependent activation of type I NKT cells. Type II NKT activation required hepatocyte expression of microsomal triglyceride transfer protein (MTP) and CD1d (16). In a murine acute hepatitis B transgenic model, NKG2D-dependent activation of type II NKT cells has been shown to result in liver damage (59).

\section{Type II NKT Cells in Tumor Immunity}

Similar to the immune responses in liver, type I and type II NKT cells have been shown to play opposing roles in tumor immunity

\section{References}

1. Bendelac A, Savage PB, Teyton L. The biology of NKT cells. Annu Rev Immunol (2007) 25:297-336. doi:10.1146/annurev.immunol.25.022106.141711

2. Brigl M, Brenner MB. CD1: antigen presentation and T cell function. Annu Rev Immunol (2004) 22:817-90. doi:10.1146/annurev.immunol.22.012703.104608

3. Godfrey DI, Stankovic S, Baxter AG. Raising the NKT cell family. Nat Immunol (2010) 11(3):197-206. doi:10.1038/ni.1841

4. Arrenberg P, Halder R, Kumar V. Cross-regulation between distinct natural killer T cell subsets influences immune response to self and foreign antigens. J Cell Physiol (2009) 218(2):246-50. doi:10.1002/jcp.21597

5. Kumar V, Delovitch TL. Different subsets of natural killer T cells may vary in their roles in health and disease. Immunology (2014) 142(3):321-36. doi:10.1111/ imm. 12247

6. Rhost S, Sedimbi S, Kadri N, Cardell SL. Immunomodulatory type II natural killer T lymphocytes in health and disease. Scand Jimmunol (2012) 76(3):246-55. doi:10.1111/j.1365-3083.2012.02750.x
(10, 60). Type I NKT cells are usually associated with the promotion of tumor immunity, whereas type II NKT cells are associated with its suppression (61). Thus, type I NKT cells were found to induce lysis of tumor cells directly via a perforin/ granzyme-dependent mechanism or indirectly by induction of Th1 cytokine secretion and activation of NK and DC cells. By contrast, type II NKT cells have shown immunosuppressive activity down-regulating tumor immunosurveillance (60, 62-64). Type II NKT cell-induced tumor suppression can be mediated by IL-13 secretion resulting in the activation of TGF- $\beta$-secreting MDSCs that inhibit tumor-specific $\mathrm{CD}^{+} \mathrm{T}$ cells or type I NKT cells. In humans, Chang et al. have also shown an increase in IL-13-secreting lyso-PC-reactive type II NKT cells in multiple myeloma patients (18). Interestingly, type I NKT cells are decreased in these patients, suggesting opposing roles, as their increased frequency is associated with better prognosis.

\section{Future Studies and Challenges}

Availability of stable reagents for analysis of type I NKT cells has resulted in characterization of changes in their frequency and phenotype in humans in different disease conditions, including autoimmune and infectious diseases and cancer. A detailed characterization of type II NKT cell repertoires and their ligands in humans is required for a broader understanding of their physiological role in health and in disease. A recent study suggesting a role for lyso-glucosylsphingosine (lyso-GL1)-reactive type II NKT cells in Gaucher disease is an important development (19). Together, all of these observations indicate that it may be possible in the future to differentially activate or inhibit type I and type II NKT cells for the development of novel immunotherapeutic protocols in altering the course of cancer and both infectious and autoimmune diseases.

\section{Acknowledgments}

This work was supported by grants from the National Institutes of Health, USA, R01 CA100660 and R01 AA020864 (VK) and from the Juvenile Diabetes Research Foundation (JDRF) grants 24-2007-362 (VK).

7. Brennan PJ, Brigl M, Brenner MB. Invariant natural killer T cells: an innate activation scheme linked to diverse effector functions. Nat Rev Immunol (2013) 13(2):101-17. doi:10.1038/nri3369

8. Zhao J, Weng X, Bagchi S, Wang CR. Polyclonal type II natural killer T cells require PLZF and SAP for their development and contribute to CpG-mediated antitumor response. Proc Natl Acad Sci U S A (2014) 111(7):2674-9. doi:10.1073/ pnas.1323845111

9. Godfrey DI, Kronenberg M. Going both ways: immune regulation via CD1ddependent NKT cells. JClin Invest (2004) 114(10):1379-88. doi:10.1172/JCI23594

10. Terabe M, Berzofsky JA. NKT cells in immunoregulation of tumor immunity: a new immunoregulatory axis. Trends Immunol (2007) 28(11):491-6. doi:10.1016/j. it.2007.05.008

11. Kronenberg $M$, Kinjo Y. Innate-like recognition of microbes by invariant natural killer T cells. Curr Opin Immunol (2009) 21(4):391-6. doi:10.1016/j. coi.2009.07.002

12. Arrenberg P, Halder R, Dai Y, Maricic I, Kumar V. Oligoclonality and innate-like features in the TCR repertoire of type II NKT cells reactive to a beta-linked 
self-glycolipid. Proc Natl Acad Sci U S A (2010) 107(24):10984-9. doi:10.1073/ pnas. 1000576107

13. Jahng A, Maricic I, Aguilera C, Cardell S, Halder RC, Kumar V. Prevention of autoimmunity by targeting a distinct, noninvariant CD1d-reactive $\mathrm{T}$ cell population reactive to sulfatide. J Exp Med (2004) 199(7):947-57. doi:10.1084/ jem. 20031389

14. Rhost S, Lofbom L, Rynmark BM, Pei B, Mansson JE, Teneberg S, et al. Identification of novel glycolipid ligands activating a sulfatide-reactive, CD1d-restricted, type II natural killer T lymphocyte. Eur J Immunol (2012) 42(11):2851-60. doi:10.1002/ eji.201142350

15. Tatituri RV, Watts GF, Bhowruth V, Barton N, Rothchild A, Hsu FF, et al. Recognition of microbial and mammalian phospholipid antigens by NKT cells with diverse TCRs. Proc Natl Acad Sci US A (2013) 110(5):1827-32. doi:10.1073/ pnas. 1220601110

16. Zeissig S, Murata K, Sweet L, Publicover J, Hu Z, Kaser A, et al. Hepatitis B virus-induced lipid alterations contribute to natural killer $\mathrm{T}$ cell-dependent protective immunity. Nat Med (2012) 18(7):1060-8. doi:10.1038/nm.2811

17. Maricic I, Girardi E, Zajonc DM, Kumar V. Recognition of lysophosphatidylcholine by type II NKT cells and protection from an inflammatory liver disease. J Immunol (2014) 193(9):4580-9. doi:10.4049/jimmunol.1400699

18. Chang DH, Deng H, Matthews P, Krasovsky J, Ragupathi G, Spisek R, et al. Inflammation-associated lysophospholipids as ligands for CD1d-restricted T cells in human cancer. Blood (2008) 112(4):1308-16. doi:10.1182/blood-2008-04-149831

19. Nair S, Boddupalli CS, Verma R, Liu J, Yang R, Pastores GM, et al. Type II NKT-TFH cells against Gaucher lipids regulate B-cell immunity and inflammation. Blood (2015) 125(8):1256-71. doi:10.1182/blood-2014-09-600270

20. Girardi E, Maricic I, Wang J, Mac TT, Iyer P, Kumar V, et al. Type II natural killer $\mathrm{T}$ cells use features of both innate-like and conventional $\mathrm{T}$ cells to recognize sulfatide self antigens. Nat Immunol (2012) 13(9):851-6. doi:10.1038/ni.2371

21. Patel O, Pellicci DG, Gras S, Sandoval-Romero ML, Uldrich AP, Mallevaey T, et al. Recognition of CD1d-sulfatide mediated by a type II natural killer T cell antigen receptor. Nat Immunol (2012) 13(9):857-63. doi:10.1038/ni.2372

22. Park SH, Weiss A, Benlagha K, Kyin T, Teyton L, Bendelac A. The mouse CD1drestricted repertoire is dominated by a few autoreactive $\mathrm{T}$ cell receptor families. J Exp Med (2001) 193(8):893-904. doi:10.1084/jem.193.8.893

23. Brigl M, Tatituri RV, Watts GF, Bhowruth V, Leadbetter EA, Barton N, et al. Innate and cytokine-driven signals, rather than microbial antigens, dominate in natural killer T cell activation during microbial infection. J Exp Med (2011) 208(6):1163-77. doi:10.1084/jem.20102555

24. Kinjo Y, Kitano N, Kronenberg M. The role of invariant natural killer T cells in microbial immunity. J Infect Chemother (2013) 19(4):560-70. doi:10.1007/ s10156-013-0638-1

25. Holzapfel KL, Tyznik AJ, Kronenberg M, Hogquist KA. Antigen-dependent versus -independent activation of invariant NKT cells during infection. J Immunol (2014) 192(12):5490-8. doi:10.4049/jimmunol.1400722

26. Roy KC, Maricic I, Khurana A, Smith TR, Halder RC, Kumar V. Involvement of secretory and endosomal compartments in presentation of an exogenous self-glycolipid to type II NKT cells. J Immunol (2008) 180(5):2942-50. doi:10.4049/ jimmunol.180.5.2942

27. Subramanian L, Blumenfeld H, Tohn R, Ly D, Aguilera C, Maricic I, et al. NKT cells stimulated by long fatty acyl chain sulfatides significantly reduce the incidence of type 1 diabetes in nonobese diabetic mice [corrected]. PLoS One (2012) 7(5):e37771. doi:10.1371/journal.pone.0037771

28. Halder RC, Aguilera C, Maricic I, Kumar V. Type II NKT cell-mediated anergy induction in type I NKT cells prevents inflammatory liver disease. J Clin Invest (2007) 117(8):2302-12. doi:10.1172/JCI31602

29. Halder RC, Jahng A, Maricic I, Kumar V. Mini review: immune response to myelin-derived sulfatide and CNS-demyelination. Neurochem Res (2007) 32(2):257-62. doi:10.1007/s11064-006-9145-4

30. Maricic I, Halder R, Bischof F, Kumar V. Dendritic cells and anergic type I NKT cells play a crucial role in sulfatide-mediated immune regulation in experimental autoimmune encephalomyelitis. J Immunol (2014) 193(3):1035-46. doi:10.4049/ jimmunol.1302898

31. Arrenberg P, Maricic I, Kumar V. Sulfatide-mediated activation of type II natural killer T cells prevents hepatic ischemic reperfusion injury in mice. Gastroenterology (2011) 140(2):646-55. doi:10.1053/j.gastro.2010.10.003

32. Maricic I, Sheng H, Marrero I, Seki E, Kisseleva T, Chaturvedi S, et al. Inhibition of type I NKT cells by retinoids or following sulfatide-mediated activation of type
II NKT cells attenuates alcoholic liver disease. Hepatology (2015) 61(4):1357-69. doi:10.1002/hep.27632

33. Kadri N, Korpos E, Gupta S, Briet C, Lofbom L, Yagita H, et al. CD4(+) type II NKT cells mediate ICOS and programmed death-1-dependent regulation of type 1 diabetes. J Immunol (2012) 188(7):3138-49. doi:10.4049/jimmunol.1101390

34. Parekh VV, Wu L, Olivares-Villagomez D, Wilson KT, Van Kaer L. Activated invariant NKT cells control central nervous system autoimmunity in a mechanism that involves myeloid-derived suppressor cells. J Immunol (2013) 190(5):1948-60. doi:10.4049/jimmunol.1201718

35. Kumar V. NKT-cell subsets: promoters and protectors in inflammatory liver disease. J Hepatol (2013) 59(3):618-20. doi:10.1016/j.jhep.2013.02.032

36. Brandl C, Ortler S, Herrmann T, Cardell S, Lutz MB, Wiendl H. B7-H1-deficiency enhances the potential of tolerogenic dendritic cells by activating CD1drestricted type II NKT cells. PLoS One (2010) 5(5):e10800. doi:10.1371/journal. pone. 0010800

37. Yang SH, Lee JP, Jang HR, Cha RH, Han SS, Jeon US, et al. Sulfatide-reactive natural killer T cells abrogate ischemia-reperfusion injury. J Am Soc Nephrol (2011) 22(7):1305-14. doi:10.1681/ASN.2010080815

38. Zeissig S, Blumberg RS. Commensal microbiota and NKT cells in the control of inflammatory diseases at mucosal surfaces. Curr Opin Immunol (2013) 25(6):690-6. doi:10.1016/j.coi.2013.09.012

39. Liao CM, Zimmer MI, Wang CR. The functions of type I and type II natural killer T cells in inflammatory bowel diseases. Inflamm Bowel Dis (2013) 19(6):1330-8. doi:10.1097/MIB.0b013e318280ble3

40. Fuss IJ, Heller F, Boirivant M, Leon F, Yoshida M, Fichtner-Feigl S, et al. Nonclassical CD1d-restricted NK T cells that produce IL-13 characterize an atypical Th2 response in ulcerative colitis. J Clin Invest (2004) 113(10):1490-7. doi:10.1172/JCI19836

41. Fuss IJ, Joshi B, Yang Z, Degheidy H, Fichtner-Feigl S, de Souza H, et al. IL-13Ralpha2-bearing, type II NKT cells reactive to sulfatide self-antigen populate the mucosa of ulcerative colitis. Gut (2014) 63(11):1728-36. doi:10.1136/ gutjnl-2013-305671

42. Liao CM,Zimmer MI, Shanmuganad S, Yu HT, Cardell SL, Wang CR. Dysregulation of CD1d-restricted type ii natural killer T cells leads to spontaneous development of colitis in mice. Gastroenterology (2012) 142(2): 326-34.e1-2. doi:10.1053/j. gastro.2011.10.030

43. Exley MA, Hand L, O'Shea D, Lynch L. Interplay between the immune system and adipose tissue in obesity. J Endocrinol (2014) 223(2):R41-8. doi:10.1530/ JOE-13-0516

44. Hams E, Locksley RM, McKenzie AN, Fallon PG. Cutting edge: IL-25 elicits innate lymphoid type 2 and type II NKT cells that regulate obesity in mice. J Immunol (2013) 191(11):5349-53. doi:10.4049/jimmunol.1301176

45. Wu D, Molofsky AB, Liang HE, Ricardo-Gonzalez RR, Jouihan HA, Bando JK, et al. Eosinophils sustain adipose alternatively activated macrophages associated with glucose homeostasis. Science (2011) 332(6026):243-7. doi:10.1126/ science. 1201475

46. Maricic I, Sheng H, Marrero I, Seki E, Kisseleva T, Chaturvedi S, et al. Inhibition of type I natural killer T cells by retinoids or following sulfatide-mediated activation of type II natural killer T cells attenuates alcoholic liver disease in mice. Hepatology (2015) 61(4):1357-69. doi:10.1002/hep.27632

47. Mathews S, Feng D, Maricic I, Ju C, Kumar V, Gao B. Invariant natural killer $\mathrm{T}$ cells contribute to chronic-plus-binge ethanol-mediated liver injury by promoting hepatic neutrophil infiltration. Cell Mol Immunol (2015). doi:10.1038/ cmi.2015.06

48. Yanagisawa K, Yue S, van der Vliet HJ, Wang R, Alatrakchi N, Golden-Mason $\mathrm{L}$, et al. Ex vivo analysis of resident hepatic pro-inflammatory CD1d-reactive T cells and hepatocyte surface CD1d expression in hepatitis C.J Viral Hepat (2013) 20(8):556-65. doi:10.1111/jvh.12081

49. Adler M, Taylor S, Okebugwu K, Yee H, Fielding C, Fielding G, et al. Intrahepatic natural killer $\mathrm{T}$ cell populations are increased in human hepatic steatosis. World J Gastroenterol (2011) 17(13):1725-31. doi:10.3748/wjg.v17.i13.1725

50. Syn WK, Oo YH, Pereira TA, Karaca GF, Jung Y, Omenetti A, et al. Accumulation of natural killer $\mathrm{T}$ cells in progressive nonalcoholic fatty liver disease. Hepatology (2010) 51(6):1998-2007. doi:10.1002/hep.23599

51. Tajiri K, Shimizu Y, Tsuneyama K, Sugiyama T. Role of liver-infiltrating $\mathrm{CD} 3+\mathrm{CD} 56+$ natural killer $\mathrm{T}$ cells in the pathogenesis of nonalcoholic fatty liver disease. Eur J Gastroenterol Hepatol (2009) 21(6):673-80. doi:10.1097/ MEG.0b013e32831bc3d6 
52. Tupin E, Kinjo Y, Kronenberg M. The unique role of natural killer T cells in the response to microorganisms. Nat Rev Microbiol (2007) 5(6):405-17. doi:10.1038/ nrmicro1657

53. Duthie MS, Kahn M, White M, Kapur RP, Kahn SJ. Critical proinflammatory and anti-inflammatory functions of different subsets of CD1d-restricted natural killer T cells during Trypanosoma cruzi infection. Infect Immun (2005) 73(1):181-92. doi:10.1128/IAI.73.1.181-192.2005

54. Mallevaey T, Zanetta JP, Faveeuw C, Fontaine J, Maes E, Platt F, et al. Activation of invariant NKT cells by the helminth parasite Schistosoma mansoni. J Immunol (2006) 176(4):2476-85. doi:10.4049/jimmunol.176.4.2476

55. Sundell IB, Halder R, Zhang M, Maricic I, Koka PS, Kumar V. Sulfatide administration leads to inhibition of HIV-1 replication and enhanced hematopoeisis. J Stem Cells (2010) 5(1):33-42. doi:jsc.2010.5.1.33

56. Fernandez CS, Kelleher AD, Finlayson R, Godfrey DI, Kent SJ. NKT cell depletion in humans during early HIV infection. Immunol Cell Biol (2014) 92(7):578-90. doi:10.1038/icb.2014.25

57. Kwiecinski J, Rhost S, Lofbom L, Blomqvist M, Mansson JE, Cardell SL, et al. Sulfatide attenuates experimental Staphylococcus aureus sepsis through a CD1ddependent pathway. Infect Immun (2013) 81(4):1114-20. doi:10.1128/IAI.01334-12

58. Fisicaro P, Valdatta C, Boni C, Massari M, Mori C, Zerbini A, et al. Early kinetics of innate and adaptive immune responses during hepatitis B virus infection. Gut (2009) 58(7):974-82. doi:10.1136/gut.2008.163600

59. Baron JL, Madri JA, Ruddle NH, Hashim G, Janeway CA Jr. Surface expression of alpha 4 integrin by CD4 T cells is required for their entry into brain parenchyma. J Exp Med (1993) 177(1):57-68. doi:10.1084/jem.177.1.57

60. Ambrosino E, Terabe M, Halder RC, Peng J, Takaku S, Miyake S, et al. Crossregulation between type I and type II NKT cells in regulating tumor immunity: a new immunoregulatory axis. J Immunol (2007) 179(8):5126-36. doi:10.4049/ jimmunol.179.8.5126

61. Robertson FC, Berzofsky JA, Terabe M. NKT cell networks in the regulation of tumor immunity. Front Immunol (2014) 5:543. doi:10.3389/fimmu.2014.00543

62. Hix LM, Shi YH, Brutkiewicz RR, Stein PL, Wang CR, Zhang M. CD1d-expressing breast cancer cells modulate NKT cell-mediated antitumor immunity in a murine model of breast cancer metastasis. PLoS One (2011) 6(6):e20702. doi:10.1371/ journal.pone.0020702

63. Izhak L, Ambrosino E, Kato S, Parish ST, O’Konek JJ, Weber H, et al. Delicate balance among three types of $\mathrm{T}$ cells in concurrent regulation of tumor immunity. Cancer Res (2013) 73(5):1514-23. doi:10.1158/0008-5472.CAN-12-2567

64. Renukaradhya GJ, Khan MA, Vieira M, Du W, Gervay-Hague J, Brutkiewicz RR. Type I NKT cells protect (and type II NKT cells suppress) the host's innate antitumor immune response to a B-cell lymphoma. Blood (2008) 111(12):5637-45. doi:10.1182/blood-2007-05-092866

Conflict of Interest Statement: The authors declare that the research was conducted in the absence of any commercial or financial relationships that could be construed as a potential conflict of interest.

Copyright (C) 2015 Marrero, Ware and Kumar. This is an open-access article distributed under the terms of the Creative Commons Attribution License (CC BY). The use, distribution or reproduction in other forums is permitted, provided the original author(s) or licensor are credited and that the original publication in this journal is cited, in accordance with accepted academic practice. No use, distribution or reproduction is permitted which does not comply with these terms. 